\title{
Successful Surgical Rescue of Hepatic Encephalopathy due to Anal Fissure in the Case of Acute Myeloid Leukemia
}

\author{
Tsukasa Nakamura ${ }^{\mathrm{a}, \mathrm{c}}$, Kaori Okugawa ${ }^{\mathrm{b}}$, Hirotaka Sako ${ }^{\mathrm{b}}$, Norio Yoshimura ${ }^{\mathrm{a}}$
}

\begin{abstract}
Anal fissures and other anorectal complications are relatively common conditions, which are rarely fatal. However, it is important to understand that these conditions could progress to lethal infections in immunocompromised patients. On the other hand, Hepatic encephalopathy (also known as portosystemic encephalopathy) is a potentially-reversible, life-threatening, systemic, neuropsychiatric disorder, which occurs in the setting of liver failure. Hepatic encephalopathy can occur in either acute or chronic liver disease, or, in the case of portal-systemic shunting, without associated intrinsic liver disease. Hepatic encephalopathy due to anal fissure is relatively rare. In cases of perirectal cellulitis caused by Escherichia Coli (E. Coli) or other enteric bacteria large amounts of NH3 are produced, especially in immunocompromised patients. This NH3 is subsequently drained by the middle or lower rectal veins from the rectal venous plexus to the systemic circulation. Consequently, patients can experience severe hepatic encephalopathy in spite of normal liver function. To our knowledge, this is the first published case of an anal fissure presenting with hepatic encephalopathy during therapy-related neutropenia in a patient with AML. Surgical intervention with sigmoid colostomy and perirectal drainage is the procedure of choice to treat life-threatening hepatic encephalopathy in immunocompromised patients with anorectal cellulitis not responding to conservative therapy. For this reason, we also chose to perform a sigmoid colostomy with drainage of the perirectal cellulitis.
\end{abstract}

\footnotetext{
Manuscript accepted for publication September 24, 2012

${ }^{a}$ Department of Transplant and General Surgery, Kyoto Prefectural University of Medicine, address: Kajii-cho 465, Kamigyo-ku, Kyotoprefecture, Japan

${ }^{\mathrm{b}}$ Department of Surgery, Omihachiman Medical Community Center, address: Tsuchida-cho 1379, Omihachiman-city, Shiga-prefecture, Japan

${ }^{\mathrm{c} C}$ Corresponding author: Tsukasa Nakamura, Department of Transplant and General Surgery, Kyoto Prefectural University of Medicine, address: Kajii-cho 465, Kamigyo-ku, Kyoto-prefecture, Japan.

Email: tsukasa@koto.kpu-m.ac.jp
}

doi: http://dx.doi.org/10.4021/jmc890w
Keywords: Hepatic encephalopathy; Hyperammonemia; Anal fissure; Leukemia; Pancytopenia; Immunocompromised

\section{Introduction}

Over the last four decades, advances in the supportive care of immunocompromised patients have contributed to a significant decrease in infection-associated morbidity and mortality [1-2]. Previously, several clinical studies identified risk factors for anorectal infection in immunocompromised patients [3-5]. Generally, anorectal infections in immunocompromised patients can be successfully managed with antibiotic therapy and local care alone [2]. Surgery, however, is needed if there is evidence of progressive infection or systemic disturbances, as is the case in patients who exhibit hepatic encephalopathy. Hepatic encephalopathy (also known as portosystemic encephalopathy) presents with confusion, altered level of consciousness and coma, usually as a result of liver failure, which may ultimately result in death. Far less commonly, perirectal cellulitis may also cause hepatic encephalopathy as a result of NH3 drainage from the rectal venous plexus to systemic circulation [6-7]. To our knowledge, however, there has been no report of hepatic encephalopathy caused by an anal fissure in an immunocompromised patient with AML. In this article, we report a case of successful surgical rescue for a patient presenting with hepatic encephalopathy due to an anal fissure in a patient with AML.

\section{Case Report}

A 23-year-old woman presented to our hospital complaining of easy fatigability, fever of about 7 day's duration and anal pain. Physical examination was remarkable for ecchymosis of her arms and legs, and an anal fissure. Hematologic studies showed a white blood cell (WBC) count of $107,900 / \mu \mathrm{L}$, Hemoglobin $(\mathrm{HgB})$ of $11.0 \mathrm{~g} / \mathrm{dL}$, Platelet count of $30,000 /$ $\mu \mathrm{L}$, a protholombin time of (PT sec) $14.5 \mathrm{sec}$ Fibrinogen of $249.0 \mathrm{mg} / \mathrm{dL}$, Fibrin degradation product (FDP) of 28.0 
Table 1. Laboratory Examination on Admission

\begin{tabular}{ll} 
White blood cell & $107.9 \times 10^{9} / \mathrm{L}$ \\
Red blood cell & $3.42 \times 10^{12} / \mathrm{L}$ \\
Hemoglobin & $11.0 \mathrm{~g} / \mathrm{dL}$ \\
Platelet & $30 \times 10^{9} / \mathrm{L}$ \\
PT sec & $14.5 \mathrm{sec}$ \\
APTT sec & $31.4 \mathrm{sec}$ \\
& \\
Total protein & $7.8 \mathrm{~g} / \mathrm{dL}$ \\
Albumin & $4.7 \mathrm{~g} / \mathrm{dL}$ \\
Total Bilirubin & $0.6 \mathrm{mg} / \mathrm{dL}$ \\
Asparate aminotransferase & $26 \mathrm{IU} / \mathrm{L}$ \\
Alanine aminotransferase & $42 \mathrm{IU} / \mathrm{L}$ \\
Gamma glutamyl transpeptidase & $22 \mathrm{IU} / \mathrm{L}$ \\
Lactate dehydrogenase & $348 \mathrm{IU} / \mathrm{L}$ \\
Amylase & $42 \mathrm{IU} / \mathrm{L}$ \\
Blood urea nitrogen & $8.4 \mathrm{mg} / \mathrm{dL}$ \\
Creatinine & $0.56 \mathrm{mg} / \mathrm{dL}$ \\
Na & $142 \mathrm{mEq} / \mathrm{L}$ \\
K & $3.4 \mathrm{mEq} / \mathrm{L}$ \\
Cl & $103 \mathrm{mEq} / \mathrm{L}$ \\
Glucose & $104 \mathrm{mg} / \mathrm{dL}$ \\
HbAlc & $6.4 \%$ \\
Immunoglobulin G & $1,497 \mathrm{mg} / \mathrm{dL}$ \\
Immunoglobulin A & $176 \mathrm{mg} / \mathrm{dL}$ \\
Immunoglobulin M & $140 \mathrm{mg} / \mathrm{dL}$ \\
HBs-Ag & Negative \\
HCV-Ab & Negative \\
HIV-Ab & Negative \\
& \\
\hline
\end{tabular}

PT: prothrombin time; APTT: activated partial thromboplastin time; HBs-Ag: hepatitis B surface antigen; HCV-Ab: hepatitis C virus antibody; HIV-Ab: human immunodeficiency virus antibody.

$\mu \mathrm{g} / \mathrm{mL}$. Liver function tests showed total bilirubin, asparate aminotransferase (AST), alanine aminotransferase (ALT), and gamma-glutamyl transpeptidase ( $\gamma$-GTP) levels were of $0.6 \mathrm{mg} / \mathrm{dL}, 26 \mathrm{IU} / \mathrm{L}, 42 \mathrm{IU} / \mathrm{L}$, and $22 \mathrm{IU} / \mathrm{L}$ respectively (Table 1).Based on an extremely high WBC count, we suspected new onset leukemia and subsequent bone marrow aspiration was performed. The WBC differential revealed that blasts accounted for $92.4 \%$, consequently acute myeloid leukemia (AML) M1 was diagnosed. In addition, the FLT3/ ITD mutation was detected on genetic analysis. Combination chemotherapy with Idarubicin (IDR) and Cytarabin (Ara-C) was immediately initiated and within 4 day's of admission her WBC count was dramatically reduced to under $500 / \mu \mathrm{L}$. Blood cultures were drawn, and the patient was started on cefepime (CFPM). Her chest X ray and cytomegalovirus pp65 antigen (C7HRP) were both negative, but she continued to complain of anal pain and discomfort. E. Coli was detected in her blood cultures and the IV antibiotics were changed to meropenem (MEPM) based on the sensitivity results. However, anti-microbial therapy alone was not successful as our patient became increasingly confused and was disoriented to time and place. This corresponded to Grade 2 hepatic encephalopathy as described by the West Heaven Criteria (Table 2).Head computed tomography (CT), chest X ray, and arterial blood gas examinations were unremarkable. Blood examination revealed that $\mathrm{NH} 3$ was elevated to $235 \mu \mathrm{g} / \mathrm{dL}$, AST and ALT levels were 40 and $148 \mathrm{IU} / \mathrm{L}$ respectively, and the PT was $16.5 \mathrm{sec}$, Alb was $3.0 \mathrm{~g} / \mathrm{dL}$ (Table 3). We were suspicious that the anal fissure had progressed to perirectal cellulitis and was the cause of her hepatic encephalopathy and E. coli bacteremia. The patient then underwent a whole body CT scan which showed did in fact reveal perirectal cellulitis without abscess formation and no other abnormalities (Fig. 1, 2). The following day her hepatic encephalopathy worsened to Grade 3 and we decided that the patient need immediate surgical rescue. The patient subsequently underwent a diverting end-sigmoid colostomy, with drainage of the perirectal cellulitis under a general anesthesia. In addi-

Table 2. West Heaven Criteria for Semiquantative Grading of Mental State

Grade $1 \quad$ Trivial lack of awareness, Euphoria or anxiety
Shortened attention span
Impaired performance of addition
Grade $2 \quad$ Lethargy or apathy
Minimal disorientation for time or place
Subtle personality change, Inappropriate behaviour
Impaired performance of subtraction
Grade $3 \quad$ Comnolence to semistupor, but responsive to verbal stimuli
Confusion, Gross disorientation
Grade 4


Table 3. Laboratory Examination on the Onset of Hepatic Encephalopathy

$\begin{array}{ll}\text { White blood cell } & 0.4 \times 10^{9} / \mathrm{L} \\ \text { Red blood cell } & 2.56 \times 10^{12} / \mathrm{L} \\ \text { Hemoglobin } & 8.1 \mathrm{~g} / \mathrm{dL} \\ \text { Platelet } & 37 \times 10^{9} / \mathrm{L} \\ \text { PT sec } & 16.5 \mathrm{sec} \\ \text { APTT sec } & 37.7 \mathrm{sec} \\ \text { Total protein } & 6.6 \mathrm{~g} / \mathrm{dL} \\ \text { Albumin } & 3.0 \mathrm{~g} / \mathrm{dL} \\ \text { Total Bilirubin } & 1.2 \mathrm{mg} / \mathrm{dL} \\ \text { Asparate aminotransferase } & 40 \mathrm{IU} / \mathrm{L} \\ \text { Alanine aminotransferase } & 148 \mathrm{IU} / \mathrm{L} \\ \text { Lactate dehydrogenase } & 92 \mathrm{IU} / \mathrm{L} \\ \text { Amylase } & 42 \mathrm{IU} / \mathrm{L} \\ \text { Blood urea nitrogen } & 14.3 \mathrm{mg} / \mathrm{dL} \\ \text { Creatinine } & 0.49 \mathrm{mg} / \mathrm{dL} \\ \text { Na } & 140 \mathrm{mEq} / \mathrm{L} \\ \text { K } & 4.6 \mathrm{mEq} / \mathrm{L} \\ \text { Cl } & 104 \mathrm{mEq} / \mathrm{L} \\ \text { Glucose } & 111 \mathrm{mg} / \mathrm{dL} \\ \text { HbAlc } & 6.4 \% \\ \text { Ammonia } & 235 \mu \mathrm{g} / \mathrm{dL} \\ & \end{array}$

PT: prothrombin time; APTT: activated partial thromboplastin time.

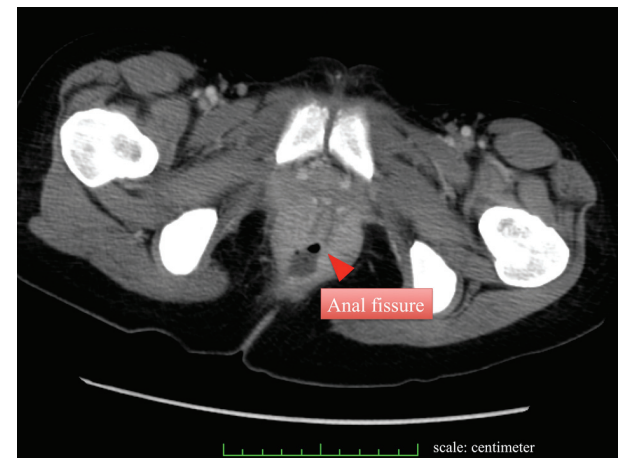

Figure 1. CT reveals anal fissure without a significant abscess formation.

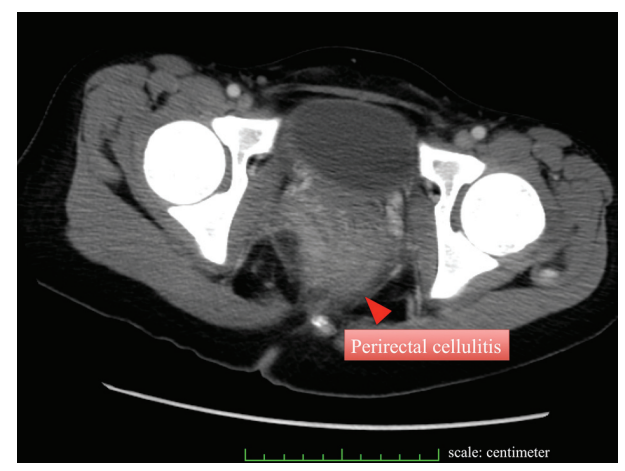

Figure 2. CT also demonstrates perirectal cellulitis without other abnormalities.

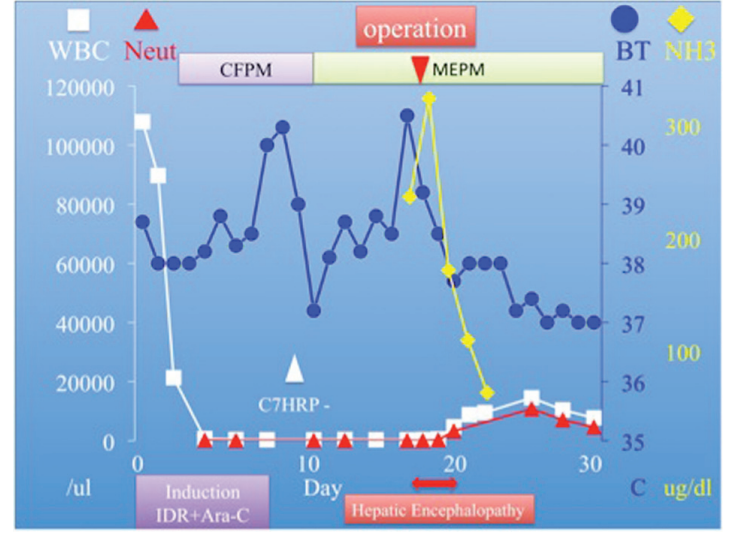

Figure 3. Clinical course demonstrates a significant reduction in the level of ammnonia after surgery.

tion, were peatedly irrigated the rectum with amikacin enemas. Right after surgery, blood tests revealed the highest yet level of NH3 at $325 \mu \mathrm{g} / \mathrm{dL}$. We continued the amikacin enemas and started lactulose. Soon after surgery the NH3 dropped precipitously and leveled off. At the same time, her level of consciousness improved and she became completely coherent without signs of hepatic encephalopathy. The E. Coli sepsis resolved (Fig. 3) with intravenous MEPM 2 g/ day for 16-days duration. She has now completed the 4th consolidation chemotherapy and she is currently awaiting bone marrow transplantation.

\section{Discussion}

A classification of hepatic encephalopathy was introduced at the World Congress of Gastroenterology 1998 in Vienna. According to this classification, hepatic encephalopathy is subdivided in type A, B and C depending on the underlying cause (Table 4). Those with severe encephalopathy (Grade 3 and 4) are at risk of airway compromise due to decreased protective reflexes such as the gag reflex. This can lead to respiratory arrest. In such situations, transferring the patient to a higher level of care, such as an intensive care unit, and

Table 4. Hepatic Encephalopathy is Classified into 3 Types Based on the Disease State of the Liver

Hepatic encephalopathy is subdivided in type A, B and C

Type A (acute) describes hepatic encephalopathy associated with acute liver failure

Type B (bypass) is caused by portal-systemic shunting without associated intrinsic liver disease

Type C (cirrhosis) occurs in patients with cirrhosis

Classification and grading In the World Congress of Gastroenterology 1998 in Vienna. 


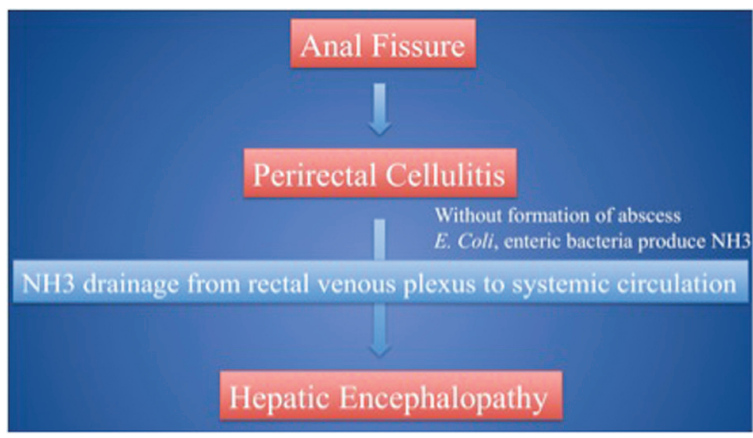

Figure 4. Patients could experience severe heaptic encephalopathy primarily due to anal fissure.

airway control is often necessary to prevent life-threatening complications (for example, aspiration or respiratory failure). The treatment of hepatic encephalopathy depends on the suspected underlying cause (types A, B or C). Generally, hepatic encephalopathy type B may arise in those who have undergone a transjugular intrahepatic portosystemic shunt (TIPS) procedure or have suffered from various venoocclusive disorders [6-8]. In most cases, this resolves either spontaneously or with the medical treatments discussed below, but in a small proportion, about 5\%, occlusion of the shunt is required to address the symptoms [9-10]. Hepatic encephalopathy sometimes occurs in leukemia patients due to hepatic infiltration classified as type A hepatic encephalopathy [11]. In this case, however, hepatic encephalopathy was classified as a subtype of type B. The patient's liver function remained almost within normal limits even after AML induction chemotherapy. Her AST, ALT, and total bilirubin were slightly elevated, but soon plateaued at around 40, $150 \mathrm{IU} / \mathrm{L}$, and $1.2 \mathrm{mg} / \mathrm{dL}$ respectively, serum Alb somewhat dropped to $3.0 \mathrm{~g} / \mathrm{dL}$, andthe PT remained steady at $16.5 \mathrm{sec}$. Viral panels did not reveal any evidence of HBV, HCV, or HIV infections [12]. CT scan did not show any hepatic infiltration which was also proved on her later clinical course. Although, it remains that elevation of ALT indicated a certain amount of liver dysfunction which seemed to be primarily due to the side effect of chemotherapy, however it is quite hard to consider around $150 \mathrm{IU} / \mathrm{L}$ transaminase as the reason of hyperammonemia. We therefore concluded, there were no signs of acute liver failure. It seems that the perirectal cellulitis produced large quantities of $\mathrm{NH} 3$ which subsequently entered the systemic circulation via the middle and lower rectal veins and through the rectal venous plexus despite the absence of portal-hypertension. Moreover, without abscess formation the $\mathrm{NH} 3$ was shunted systemically as there was nowhere for it to collect or drain (Fig. 4). This is what ultimately resulted in our patient's type B hepatic encephalopathy. Interestingly, according to the previous investigations of anorectal complications in leukemia and other cancer patients, the single most important risk factor for anorectal infection is an absolute neutropenia (defined as less than $500 / \mu \mathrm{L}$ ), and the majority of patients who develop perirec- tal infections have underlying hematological malignancies $[3,13]$. These studies illustrate that the majority of anorectal complications can be successfully managed with antibiotic therapy and local care alone. However, about $15 \%$ of patients with leukemia and $35 \%$ of patients with all cause malignancies require surgical intervention, most commonly secondary to an anorectal abscess. Most of these procedures were simple incision of and drainage of the abscess with only a minority of cases requiring debridement and diverting endsigmoid colostomy [1-2]. Generally indications for surgery include extension of cellulitis, increasing pain, the presence of fluctuance, or failure of conservative medical management. In this case, it was important to surgically control the ever-increasing level of NH3 and to treat the worsening perirectal cellulitis thus preventing even further complications. As occlusion of the rectal vasculature does not seem to be a viable option a diverting sigmoid colostomy is the procedure of choice to treat life-threatening hepatic encephalopathy. In addition, it is also essential to use lactulose and amikacin enemas.

\section{Conclusion}

In general, it is of vital importance to understand that in immunocopromised patients even an anal fissure could lead to life-threatening hepatic encephalopathy. Moreover, it is also vital not to hesitate to perform a sigmoid colostomy if medical therapy fails, although the introduction of amikacin enemas and lactulose, all together could be a factor to attribute the clinical improving. As a result of this report we would like to make clinicians more aware of hepatic encephalopathy due to anal fissure as this condition, although rare, is entirely treatable, and when recognized and managed appropriately will lead to improved survival rates.

\section{References}

1. North JH, Jr., Weber TK, Rodriguez-Bigas MA, Meropol NJ, Petrelli NJ. The management of infectious and noninfectious anorectal complications in patients with leukemia. J Am Coll Surg. 1996;183(4):322-328.

2. Lehrnbecher T, Marshall D, Gao C, Chanock SJ. A second look at anorectal infections in cancer patients in a large cancer institute: the success of early intervention with antibiotics and surgery. Infection. 2002;30(5):272276.

3. Rolston KV, Bodey GP. Diagnosis and management of perianal and perirectal infection in the granulocytopenic patient. Curr Clin Top Infect Dis. 1993;13:164-171.

4. Vanhueverzwyn R, Delannoy A, Michaux JL, Dive C. Anal lesions in hematologic diseases. Dis Colon Rectum. 1980;23(5):310-312. 
5. Angel C, Patrick CC, Lobe T, Rao B, Pui CH. Management of anorectal/perineal infections caused by Pseudomonas aeruginosa in children with malignant diseases. J Pediatr Surg. 1991;26(4):487-492; discussion 492-483.

6. Ferenci P, Lockwood A, Mullen K, Tarter R, Weissenborn K, Blei AT. Hepatic encephalopathy--definition, nomenclature, diagnosis, and quantification: final report of the working party at the 11th World Congresses of Gastroenterology, Vienna, 1998. Hepatology. 2002;35(3):716-721.

7. Diaz-Gomez D, Jover M, del-Campo JA, Galindo A, Romero-Gomez M. Experimental models for hepatic encephalopathy. Rev Esp Enferm Dig. 2011;103(10):536541.

8. Jacobson BK, Kalayoglu M. Effective early treatment of hepatic venoocclusive disease with a central splenorenal shunt in an infant. J Pediatr Surg. 1992;27(4):531-533.

9. Martinez Moreno B, Bellot P, de Espana F, Palazon JM, Such J, Perez-Mateo M. [Treatment of refractory hepatic encephalopathy associated with insertion of a transjugular intrahepatic portosystemic shunt through new endovascular techniques: a case report]. Gastroenterol Hepatol. 2011;34(7):468-473.

10. Sundaram V, Shaikh OS. Hepatic encephalopathy: pathophysiology and emerging therapies. Med Clin North Am. 2009;93(4):819-836, vii.

11. Dada R, Wilop S, Jost E, Galm O, Gassler N, Osieka R. Successful treatment of hepatic encephalopathy in a patient with acute lymphoblastic leukemia. Acta Haematol. 2009;122(4):216-220.

12. Kobessho H, Matsushita A, Takahashi K, Shimodaira M, Ishihara T, Oita T, Takahashi T. Hepatic encephalopathy in primary human immunodeficiency virus type 1 (HIV1) infection. Intern Med. 2002;41(11):1069-1072.

13. Chanock SJ, Pizzo PA. Infectious complications of patients undergoing therapy for acute leukemia: current status and future prospects. Semin Oncol. 1997;24(1):132140. 